View Article Online / Journal Homepage / Table of Contents for this issue

SCHORLEMMER ON THE HYDRIDES, ETC.

\title{
I.-On the Hydrides of the Alcohol-radicles existing in the Products of the Destructive Distillation of Cannel Coal.
}

\author{
By C. Schorlemmer,
}

Assistant in the Laboratory of Owens College, Manchester.

T'He light oils produced in the destructive distillation of coal have lately found so extended an application in the arts, that the yield of these oils, in the process of gas-making, has proved quite insufficient to meet the trade demand.

Considerable quantities of coal are, therefore, now distilled with the sole object of obtaining liquid products. The yield of volatile liquid depends, as is well known (1), upon the circumstance that the distillation is conducted at as low a temperature as possible, and (2) that the substances, when once formed, are not decomposed by exposure to a red heat.

Mr. John Barrow, of the Dalton Chemical Works, Gorton, near Manchester, has been kind enough to place a sufficient quantity of the light oils obtained by the distillation of coal at my disposal, to enable me to undertake a thorough cxamination of their chemical composition. They are obtained by Mr. Barrow, on the large scale by distilling Wigan Cannel in retorts, the lower surfaces of which are heated, whilst the upper parts are kept as cool as possible.

The crude oil possesses the peculiar smell of the compound ammonias, and when these are removed by treating the liquid with dilute sulphuric acid, the oil assumes the peculiar garlic-like smell of the higher olefines.

On submitting the oil to repeated fractional distillation, a small quantity of liquid is obtained boiling below $20^{\circ} \mathrm{C}$, a considerable quantity distils between $35^{\circ}-45^{\circ} \mathrm{C}$., much less from $45^{\circ}-65^{\circ}$, whilst abore $65^{\circ}$ about equal portions distil for every $5^{\circ}$ of increase of temperature. It was, however, found impossible to obtain a product of constant boiling point by repeated fractional distillations.

When concentrated nitric acid is brought in contact with the 
oil, so violent an oxidation occurs, that spontanenus ignition of the more volatile portions of the oil sometimes takes place. When the action is moderated by cooling, a large portion of the oil remains unacted upon, whilst considerable quantities of nitrocompounds are formed.

I confine myself, in the present communication, to the consideration of the liquids which remain unacted upon by nitric acid, and are contained in the crude oil boiling below $120^{\circ} \mathrm{C}$.

The separation of these oils by means of nitric acid is a tedious and disagreeable operation. It may, however, be easily effected by previously shaking up the crude oil with an equal rolume of ordinary sulphuric acid. The mixture becomes heated, assumes a dark colour, and gives off a smell resembling that of peppermint, and after some time sulphurous acid is evolved.

The liquids were allowed to remain in contact for several days, and were frequently shaken; the oil was then poured off, washed with water and distilled, a large quantity of tarry matter being left behind in the retort.

The distillate consisted mainly of benzol and toluol, together with the liquids unacted upon by acids. For the purpose of obtaining the latter liquids in the pure state, I have employed the method described by Greville Williams in his researches on the hydrocarbons from Boghead coal.* This method consists in repeatedly shaking the oil with concentrated nitric acid, until, on addition of water to the acid liquid, no further separation of nitro-compounds occurs. The liquid unacted upon is then washed with water, dried orer potash, and repeatedly rectified over sodium.

By fractional distillation of this liquid, the following four bodies were obtained-

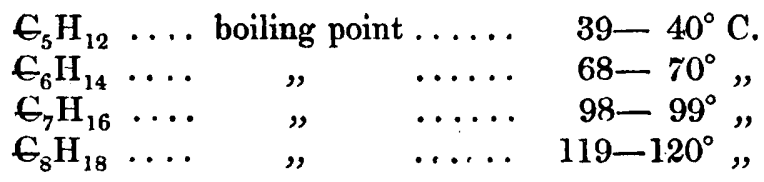

It will be shown that these liquids are the hydrides of the alcoholradicles, inasmuch as they have been transformed by the action of chlorine into their corresponding chlorides. 
THE ALCOHOL-RADICLES, ETC.

421

(1) Hydride of Amyl: $\mathrm{G}_{5} \mathrm{H}_{12}$.

Analysis : 0.1870 substance gave 0.5715 carbonic acid and $0 \cdot 2810$ water.

\begin{tabular}{lrrr} 
& \multicolumn{2}{c}{ Calculated. } & Found. \\
$\mathrm{G}_{5}$ & 60 & $\mathbf{8 3 \cdot 3 3}$ & $83 \cdot 3$ \\
$\mathrm{H}_{12}$ & 12 & $16 \cdot 67$ & $16 \cdot 7$ \\
& -72 & $\overline{100 \cdot 00}$ & \\
& & & $100 \cdot 0$
\end{tabular}

Determination of Vapour-density.
(a) Substance taken $\ldots \ldots \ldots \ldots, 0$. 1010 'grm.
Temperature of air $\ldots \ldots \ldots \quad 16^{\circ} \cdot 0 \mathrm{C}$.
Temperature of vapour...... $55^{\circ} \cdot 0 \mathrm{C}$.
Volume of vapour........ $54^{\circ} \cdot 8 \mathrm{cbc}$.
Height of barometer....... $752^{\circ} \cdot 0 \mathrm{~mm}$.
Difference of level ....... $235^{\circ} .5 \mathrm{~mm}$.

The density calculated from these numbers is $2 \cdot 523$.
(b)
Temperature of vapour....
$66^{\circ} \cdot 0 \mathrm{C}$.
Volume of vapour......... $56^{\circ} .0 \mathrm{cbc}$.
Difference of level........ $230^{\circ} \cdot 0 \mathrm{~mm}$.

Hence the vapour-density $=2 \cdot 519$.
(c) Temperature of vapour..... $91^{\circ} \cdot 0 \mathrm{C}$.
Volume of vapour........ $59^{\circ} .5 \mathrm{cbc}$.
Difference of level. ....... $220^{\circ} \cdot 0 \mathrm{~mm}$.

These numbers give the density of $2 \cdot 497$, closely corresponding to the theoretical density $2 \cdot 493$ of hydride of amyl.

Hydride of amyl is thin mobile liquid, boiling between 39 and $40^{\circ} \mathrm{C}$., and possessing a pleasant smell, resembling that of chloro form. Sp. gr. $=0.636$ at $17^{\circ} \mathrm{C}$. It burns with a bright, luminous, non-fuliginous flame. These properties, with the exception of the boiling point, correspond with those of the hydride of amyl, as described by Frankland. Although a small portion of the purified cil distils over below $30^{\circ}$ C., I 
did not succeed, after repented fractional clistillations, in obtaining a liquid having a constant boiling of $30^{\circ} \mathrm{C}$., as found by Frankland, by far the greatest part of the liquid distilling between $39-40^{\circ} \mathrm{C}$.

Greville Williams has lately shown the presence of hydride of amyl in the oils obtained by the destructive distillation of Boghead coal.*

(2) Hydride of Hexyl (Caproyl): $\mathrm{G}_{6} \mathrm{H}_{14}$.

Analysis : $0 \cdot 1460$ substance gave 0.4490 carbonic acid, and 0.2135 water.

\begin{tabular}{|c|c|c|c|}
\hline \multirow{3}{*}{$\begin{array}{l}\mathrm{G}_{6} \\
\mathrm{H}_{14}\end{array}$} & \multicolumn{2}{|c|}{ Calculated. } & Found. \\
\hline & 72 & $83 \cdot 72$ & 83.8 \\
\hline & $\dot{14}$ & $16 \cdot 28$ & $16 \cdot 3$ \\
\hline & $\overline{86}$ & & \\
\hline
\end{tabular}

Determination of Vapour-density.

Balloon with air $\ldots \ldots \ldots \ldots \ldots \ldots .23^{\circ} \cdot 449$ grms.

Temperature of air .......... $15^{\circ} \cdot 5 \mathrm{C}$.

Balloon with vapour.......... $23^{\circ} \cdot 720$ grms.

Temperature on sealing $\ldots \ldots \ldots \quad 110^{\circ} \cdot 0 \mathrm{C}$.

Capacity of balloon.......... $178^{\circ} .0 \mathrm{cbc}$.

Hence the vapour-density $=2.98$; the theoretical-density of hydride of hexyl is $\mathbf{2 \cdot 9 8}$.

Hydride of hexyl is a thin mobile liquid, of a faint but pleasant smell, burning with a luminous, slightly smoky flame. Boiling point $68-70^{\circ} \mathrm{C}$. Sp. gr. at $15^{\circ} \cdot 5=0.678$.

There can be little doubt that the body, possessing the same composition and boiling point, which Greville Williams found in the oils from Boghead coal, described in his first paper as propyl, is really hydride of hexyl. Cahours and Pelouze have lately shown that it is contained in large quantities in the American rock oil. $\dagger$

\footnotetext{
* Journ. Chem. Soc. xv., $130 . \quad$ + Phil. Trans., 1857.
} 
3. Hydride of Heptyl (Oenanthyl): $\mathrm{G}_{7} \mathrm{H}_{16}$.

Analysis:-0.1765 substance gave 0.5440 carbonic acid and 0.2570 water.

$\begin{array}{lcc} & \text { Calculated. } & \text { Found. } \\ \mathrm{G}_{7} & 84 \cdot 0 & 84 \cdot 0 \\ \mathrm{H}_{16} & 16 \cdot 0 & 16 \cdot 1 \\ & \overline{100 \cdot 0} & \\ & & 100 \cdot 1 *\end{array}$

\section{Determination of Vapour-density.}

Balloon with air.

Temperature of air.

Balloon with vapour .............

Temperature on sealing $\ldots \ldots \ldots \ldots$

Capacity of balloon $\ldots \ldots \ldots \ldots$.

Residual air $24^{\circ} \cdot 368$ grms.

$18^{\circ} \cdot 0 \mathrm{C}$.

$24^{\circ} \cdot 671$ grms.

$150^{\circ} \cdot 0 \mathrm{C}$.

$179^{\circ} \cdot 0 \mathrm{cbc}$.

$0^{\circ} \cdot 3 \mathrm{cbc}$.

These numbers give the vapour-density ..... $=3.49$ The theoretical density of hydride of heptyl is $=3.46$

Hydride of heptyl is a liquid closely resembling hydride of hexyl; it possesses a similar smell, and burns likewise with a slightly smoky flame. Boiling point $98-99^{\circ} \mathrm{C}$. Specific gravity at $17 \cdot 5^{\circ}=0.709$.

When chlorine is passed into hydride of heptyl, the liquid becomes warm, and hydrochloric acid is given off. The substitution-products formed are partially decomposed by distillation; hydrochloric acid is evolved, and carbon separates out, and the distillates assume green, blue, or purple colours, which disappear after standing for some time. A large portion however of the chlorinated liquid distils without decomposition; and from this portion, when the treatment with chlorine has not been carried too far, a considerable quantity is obtained by fractional distillation, boiling between $150-152^{\circ} \mathrm{C}$ (not corrected). This body possesses the composition and properties of chloride of heptyl $\mathrm{G}_{7} \mathrm{H}_{15} \mathrm{Cl}$.

Analysis: The combustion was effected with oxide of copper, the front part of the lube containing copper-turnings. 
0.2522 substance gave 0.5765 carbonic acid and 0.2580 water. 0.2032 substance gave 0.2120 chloride of silver and 0.0036 metallic silver.

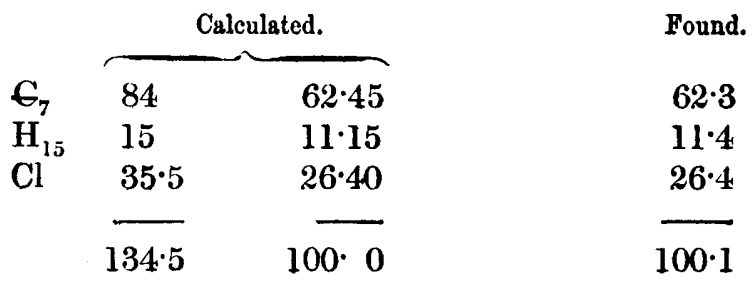

Chloride of heptyl is a colourless liquid, of a pleasant smell, burning with a smoky, green-bordered flame, and possessing the specific gravity of 0.891 at $19^{\circ} \mathrm{C}$.

When it is boiled with an alcoholic solution of acetate of potassium, chloride of potassium separates out, but the decomposition goes on very slowly. When, however, the mixture is heated in sealed tubes to about $120-130^{\circ} \mathrm{C}$, the chloride is completely decomposed in a few hours, and the liquid consists of an alcoholic solution of acetate of heptyl, which separates out on the addition of water, as a light oily liquid, having a strong and pleasant smell of pears. Treated with an aqueous solution of potash, this ether is easily decomposed and heptylic alcohol is formed, possessing a peculiar aromatic smell, resembling somewhat that of octylic alcohol as prepared from castor oil. I am at present engaged upon the investigation of the heptyl compounds.

Besides the chloride of heptyl, some chlorine-compounds, boiling at higher temperatures and distilling without decomposition, were formed, but the quantity was only small and I did not succeed in obtaining a product of constant boiling point. Heated with sodium, these chlorine-compounds are easily decomposed, and a liquid, free from chlorine is obtained, which boils between 95-- $100^{\circ} \mathrm{C}$., and possesses the peculiar smell of heptylene $\mathbf{G}_{7} \mathrm{H}_{14}$

Analysis : 0.1618 substance gave 0.5080 carbonic acid, and 0.2125 water.

Calculated.

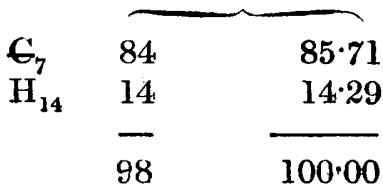

Found.

$85 \cdot 6$

$14 \cdot 6$ 
The quantity obtained was too small for determining the vapourdensity.

(4) Hydride of Octyl (Capryl) : $\boldsymbol{G}_{8} \mathrm{H}_{18}$.

Analysis : 0.2095 substance gave 0.6465 carbonic acid and 0.3040 water.

\begin{tabular}{lrrr} 
& \multicolumn{2}{c}{ Calculated. } & Found. \\
$\mathrm{E}_{8}$ & 96 & $84 \cdot 21$ & $\mathbf{8 4 \cdot 1}$ \\
$\mathrm{H}_{18}$ & 18 & $15 \cdot 79$ & $16 \cdot 1$ \\
& -114 & $-\overline{100 \cdot 0}$ & \\
& 114 & $100 \cdot 2$
\end{tabular}

Determination of Vapour-density.

Balloon with air ........... 7.098 grms.

Temperature of air .......... $15 \cdot 5^{\circ} \mathrm{C}$.

Balloon with vapour.......... 7.33 grms.

Temperature on sealing $\ldots \ldots \ldots, 1700^{\circ} \mathrm{C}$.

Capacity of balloon .......... $119.5 \mathrm{cbc}$.

The vapour-density calculated from those numbers $=\mathbf{3 . 9 8}$

The theoretical density of Hydride of Octyl is... $=3.95$

Hydride of octyl in its physical properties closely resembles the hydrides of hexyl and heptyl. It boils at $119-120^{\circ}$, and has a spec. grav. of 0.719 at $17^{\circ} .5$.

In the above-mentioned paper on the hydrocarbons from the oil obtained by the destructive distillation of Boghead coal, Greville Williams has described as butyl, a body of the above composition and boiling point, which is doubtless hydride of octyl.

The action of chlorine on hydride of octyl is similar to the action on hydride of heptyl; a large portion of the products formed are decomposed when distilled; whilst the portion which volatilizes without decomposition, yieldss by fractional distillation a considerable quantity of a liquid boiling between $170-172^{\circ} \mathrm{C}$. (not.corrected), which possesses the composition and properties of chloride of octyl $\mathrm{G}_{8} \mathrm{H}_{17} \mathrm{Cl}$.

Analysis : I. 0.1800 substance, gave 0.4250 carbonic acid, and $0 \cdot 1895$ water.

II. $0 \cdot 1697$ substance, gave 1635 chloride of silver, and 0.0015 metallic silver. 
Analysis : III. 0.2342 substance, gave 0.2280 chloride of silver, and 0.0012 metallic silver.

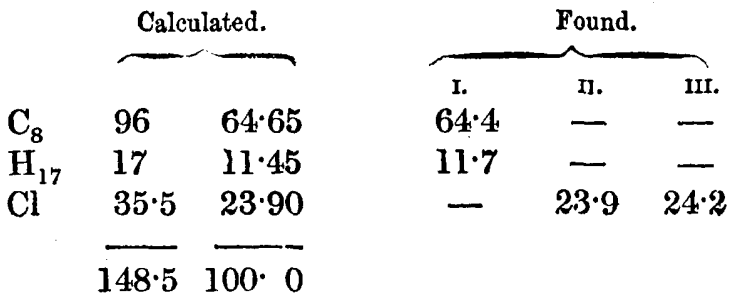

Chloride of octyl is a colourless liquid, possessing a faint but pleasant smell of oranges, and burning with a smoky, greenbordered flame. Spec. grav. $=0.892, *$ at $18^{\circ} \mathrm{C}$.

Heated with an alcoholic solution of acetate of potassium, it is decomposed in the same manner as chloride of heptyl.

The volatile chlorine-compounds which are formed together with chloride of octyl, were present in small quantity only, and I was unable to obtain a product of constant boiling point. Heated with sodium, they are easily decomposed, and I observed the formation of the blue body described by Bouis.t By repeated treatment with sodium at a higher temperature, a liquid, having a smell like that of heptylene, was obtained, boiling between $115-125^{\circ} \mathrm{C}$. By fractional distillation, the greatest portion was obtained between $115-117^{\circ} \mathrm{C}$. Bouis gives the boiling point of octylene at $125^{\circ} \mathrm{C}$.

The analysis of the liquid boiling at $115-117^{\circ} \mathrm{C}$. gave the following results :-

Substance taken........ $0 \cdot 1394$

Carbonic acid obtained .... $\quad 0.4375$

Water obtained........ 0.1845

\begin{tabular}{|c|c|c|c|}
\hline \multirow{3}{*}{$\begin{array}{l}\mathbf{G}_{8} \\
H_{16}\end{array}$} & \multicolumn{2}{|c|}{ Calculated. } & Found. \\
\hline & 96 & $85 \cdot 71$ & $85 \cdot 6$ \\
\hline & 16 & $14: 29$ & $14 \cdot 7$ \\
\hline & 112 & $100 \cdot 00$ & $100 \cdot 3$ \\
\hline
\end{tabular}

* It appears from a number of determinalions, that the spec. grav. of $G_{7} \mathrm{H}_{15} \mathrm{Cl}$ and $\mathrm{C}_{8} \mathrm{H}_{17} \mathrm{Cl}$ are very nearly the same.

+ Compt. rend xxxviii. 835 . 
GRAHAM ON CAPILLARY LIQUID TRANSPIRATION, ETC. 427

Determination of Vapour-density.

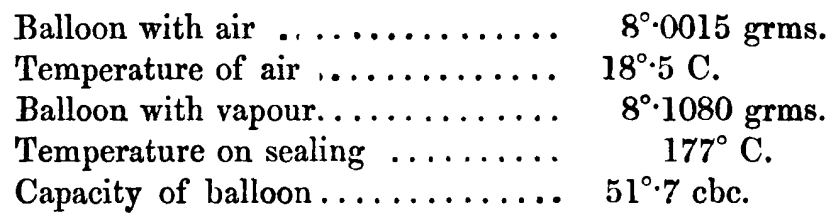

The density calculated from these numbers is . . . . . $4 \cdot 17$, whilst the theoretical density of octylene is ... $3 \cdot 88$.

I have convinced myself that the oils from Cannel coal, having a higher boiling point than those $I$ have as yet examined, likewise contain substances unalterable by the strongest acids. There appears therefore to be little doubt that the whole series of homologous hydrides are contained in the products of the distillation of coal at low temperatures; and I would venture the suggestion that the so-called paraffins, which are likewise not acted upon by strong acids, may prove to be the higher members of the same series.

In conclusion, I beg to express my best thanks to Professor Roscoe for the valuable advice which he has given me in carrying out the above investigation. 